\title{
Digestibilidade dos nutrientes e parâmetros ruminais de bovinos de corte alimentados com rações contendo bagaço de cana-de-açúcar obtido pelo método de extração por difusão ou por moagem convencional
}

\section{Mário Márcio Arakaki Rabelo1, Alexandre Vaz Pires ${ }^{2}$, Ivanete Susin ${ }^{2}$, Clayton Quirino Mendes $^{1}$, Reinaldo Cunha de Oliveira Junior ${ }^{3}$, Evandro Maia Ferreira ${ }^{1}$}

\footnotetext{
${ }^{1}$ Pós-graduação em Ciência Animal e Pastagens - ESALQ/USP - Piracicaba, SP.

2 Departamento de Zootecnia - ESALQ/USP - Piracicaba, SP.

${ }^{3}$ Departamento de Produção Animal, Universidade Federal de Goiás - Goiânia, GO.
}

RESUMO - Objetivou-se com este trabalho avaliar o efeito da utilização do bagaço de cana-de-açúcar in natura (BIN), obtido pelo método de extração do açúcar por difusão (BINdif) ou moagem convencional (BINmoa) como fonte de fibra íntegra, associado ao bagaço tratado sob pressão e vapor (BTPV) sobre a digestibilidade dos nutrientes e os parâmetros ruminais de bovinos de corte. Quatro machos da raça Nelore, não-castrados, com fístulas ruminais e peso vivo médio inicial de $380 \mathrm{~kg}$, foram distribuídos em delineamento experimental quadrado latino $4 \times 4$. Os tratamentos foram compostos das combinações dos bagaços: 5\% BINmoa + 45\% BTPV; 5\% BINdif + 45\% BTPV; $10 \%$ BINdif + 40\% BTPV; $15 \%$ BINdif $+35 \%$ BTPV. A utilização do BIN obtido por difusão, mesmo no nível mais elevado, não teve efeito sobre a digestibilidade dos nutrientes (MS, MO, PB, FDN, FDA e EE) da dieta. Entretanto, o fornecimento do bagaço obtido por difusão provocou redução nos consumos de MS, MO, PB e FDN em relação ao bagaço obtido por moagem. A produção total de ácidos graxos voláteis no rúmen, a porcentagem molar dos ácidos acético, propiônico e butírico, a relação acético/propiônico, o pH ruminal e a concentração ruminal de nirogênio amoniacal não diferiram entre os bagaços fornecidos. A utilização do bagaço obtido pelo processo de difusão ou de moagem convencional como fonte de fibra íntegra associado ao bagaço tratado sob pressão e vapor não prejudicou a digestibilidade dos nutrientes e os parâmetros ruminais de bovinos de corte alimentados com rações contendo $50 \%$ de concentrado.

Palavras-chave: ácidos graxos voláteis, fonte de fibra, Nelore, subproduto

\section{Digestibility of nutrients and ruminal characteristics in beef cattle fed rations containing sugarcane bagasse obtained by diffusion or conventional milling extraction method}

ABSTRACT - The objective of this study was to evaluate the effects of feeding sugarcane bagasse, obtained by extraction of sugar using diffusion (BINdif) or conventional milling (BINmoa) method, as a fiber source associated with bagasse treated under pressure and steam (BTPV) on nutrient digestibility and ruminal characteristics in beef cattle. Four Nellore young bulls $(380 \mathrm{~kg} \mathrm{BW})$, fitted with ruminal cannula, were assigned to a $4 \times 4$ Latin Square design. Combination of bagasse in a 50:50 (concentrate:roughage) experimental rations were: $5 \%$ BINmoa $+45 \%$ BTPV; $5 \%$ BINdif $+45 \%$ BTPV; $10 \%$ BINdif $+40 \%$ BTPV; $15 \%$ BINdif $+35 \%$ BTPV. There was no effect of using BINdif on digestibility of nutrients (DM, OM, CP, NDF, ADF and EE) of the diets. However, feeding bagasse obtained by diffusion reduced DM, OM and NDF intakes when compared to bagasse obtained by milling. Total production of ruminal volatile fatty acids, molar percentage of acetic, propionic and butyric acids, acetate:propionate ratio, ruminal $\mathrm{pH}$ and ammonia nitrogen concentration did not differ among treatments. Feeding sugarcane bagasse obtained by diffusion or conventional milling method, as source of raw fiber, associated with hydrolized bagasse by pressure and steam had no detrimental effect on nutrient digestibility and ruminal characteristics in beef cattle fed diets containing $50 \%$ concentrate.

Key Words: byproducts, fiber source, Nellore, volatile fatty acids

Este artigo foi recebido em 22/3/2007 e aprovado em 27/3/2008.

Correspondências devem ser enviadas para alvpires@esalq.usp.br 


\section{Introdução}

A diversidade de subprodutos oriundos da agroindústria sucroalcooleira gera várias alternativas alimentares, as quais podem ser amplamente utilizadas para a nutrição animal, minimizando custos para o produtor (Magalhães et al., 1999). De acordo com Ezequiel et al. (2006), nas regiões sucroalcooleiras, notadamente o Sudeste do Brasil, os bagaços de cana-de-açúcar in natura ou hidrolizado podem se acumular nas usinas com o término da safra e apresentar preços vantajosos, o que desperta o interesse dos pecuaristas pela oportunidade de redução do custo com alimentação e conseqüente aumento da rentabilidade na terminação de bovinos. O bagaço de cana-de-açúcar tratado sob pressão e vapor (BTPV) tem sido utilizado como volumoso único ou como parte da fração fibrosa da dieta de ruminantes, principalmente nas épocas de escassez de forragens ou nos confinamentos de bovinos (Borges et al., 2000). Quando utilizado em rações para confinamentos, o BTPV tem proporcionado desempenhos satisfatórios (Nussio \& Balsalobre, 1993). No entanto, entre as peculiaridades deste ingrediente, podem-se destacar o reduzido tamanho de partículas, o baixo estímulo à ruminação e o menor tempo de permanência da fibra em detergente neutro no rúmen, o que pode gerar problemas metabólicos e prejudicar o desempenho dos animais (Lanna et al., 1999).

Alguns trabalhos indicam que o bagaço de cana-deaçúcar in natura (BIN) pode ser utilizado como fonte de fibra em dietas de bovinos de corte (Berndt et al., 2002). Segundo Henrique et al. (2007), este subproduto caracteriza-se como um alimento rico em constituintes da parede celular, apresentando baixo conteúdo celular, baixa digestibilidade e baixa densidade, podendo ser considerado excelente fonte de fibra íntegra para alimentação de ruminantes, e, segundo Bulle et al. (2002a), contribui para evitar problemas metabólicos, sem prejudicar o desempenho dos animais alimentados com rações contendo alto teor de concentrado.

A extração do caldo da cana-de-açúcar pode ser realizada por meio de moendas ou de equipamentos chamados difusores. A moagem é um processo estritamente volumétrico, em que o caldo é deslocado com a passagem da cana entre dois rolos, resultando em uma porção de volume de caldo extraído e outra de bagaço. O processo de extração da sacarose da cana-de-açúcar por difusão ainda é pouco utilizado no Brasil. Esta tecnologia aproveita parte das etapas do processo de moagem, sendo que a diferença básica entre os dois processos reside na maneira de separar o caldo da fibra. De acordo com Bastos Neto (2007), o equipamento que se convencionou chamar de difusor é, na realidade, um lixiviador de cana, no qual a sacarose é extraída exclusivamente por um processo de lavagem repetitiva, passando por diluição para a solução de menor concentração. Para alcançar os elevados índices de extração, é necessário que seja possível à água entrar em contato com o maior número de células abertas. A extração através da difusão constitui um método mais eficiente que a moagem convencional e representa aumento substancial no rendimento operacional. Segundo Delgado et al. (1975), a extração do caldo passa de 90-93\% com a moagem convencional para 96-98\% com a difusão, gerando um subproduto com características físicas e químicas diferenciadas. Desta forma, o bagaço obtido por difusão apresenta-se como alternativa de fonte de fibra íntegra em rações para bovinos de corte recebendo o BTPV como principal volumoso.

Objetivou-se com este trabalho avaliar os efeitos da substituição do bagaço de cana-de-açúcar tratado sob pressão e vapor pelo bagaço de cana-de-açúcar in natura, resultante do método de extração do caldo da cana-de-açúcar por difusão ou por moagem convencional, sobre a digestibilidade dos nutrientes e os parâmetros ruminais de bovinos de corte.

\section{Material e Métodos}

O experimento foi realizado nas instalações para confinamento de bovinos do Departamento de Zootecnia, da Escola Superior de Agricultura Luiz de Queiroz (ESALQ). Foram utilizados quatro novilhos da raça Nelore com cânula ruminal e peso vivo médio inicial de $380 \mathrm{~kg}$. Os animais foram distribuídos em quadrado latino $4 \times 4 \mathrm{e}$ mantidos em baias individuais cobertas, do tipo tie stall $(1,0 \mathrm{~m} \times 2,2 \mathrm{~m})$, providas de bebedouros automáticos e cocho para alimentação.

As rações foram formuladas para atender às exigências de bovinos de corte (Tabela 1), de acordo com o NRC (1996).

As rações experimentais, todas isonitrogenadas e isoenergéticas, foram formuladas com $50 \%$ de volumoso e $50 \%$ de concentrado e diferiram quanto ao tipo do volumoso utilizado. Foram avaliados o bagaço de cana-de-açúcar in natura obtido por moagem convencional (BINmoa) e o bagaço de cana-de-açúcar in natura resultante do processo de difusão (BINdif) associados ao bagaço de cana-de-açúcar tratado sob pressão e vapor (BTPV): $5 \%$ BINmoa + 45\% BTPV; $5 \%$ BINdif + 45\% BTPV; $10 \%$ BINdif $+40 \%$ BTPV; $15 \%$ BINdif + 35\% BTPV. Os concentrados foram misturados previamente em um misturador horizontal. $\mathrm{O}$ volumoso e o concentrado, nas suas respectivas propor- 
Tabela 1 - Composição das rações experimentais (\% MS)

\begin{tabular}{|c|c|c|c|c|}
\hline \multirow[b]{2}{*}{ Ingrediente } & \multicolumn{4}{|c|}{ Tratamento $^{1}$} \\
\hline & $\begin{array}{c}5 \% \mathrm{BINmoa}^{2}+ \\
45 \% \text { BTPV }\end{array}$ & $\begin{array}{l}5 \% \text { BINdif }^{3}+ \\
45 \% \text { BTPV }\end{array}$ & $\begin{array}{l}10 \% \text { BINdif }+ \\
45 \% \text { BTPV }\end{array}$ & $\begin{array}{l}15 \% \text { BINdif + } \\
45 \% \text { BTPV }\end{array}$ \\
\hline BTPV $^{4}$ & 45,00 & 45,00 & 40,00 & 35,00 \\
\hline $\mathrm{BIN}^{5}$ & 5,00 & 5,00 & 10,00 & 15,00 \\
\hline Sorgo moído & 32,50 & 32,50 & 32,50 & 32,50 \\
\hline Levedura & 8,00 & 8,00 & 8,00 & 8,00 \\
\hline Farelo de soja & 6,00 & 6,00 & 6,00 & 6,00 \\
\hline Uréia & 1,00 & 1,00 & 1,00 & 1,00 \\
\hline Mistura mineral & 2,50 & 2,50 & 2,50 & 2,50 \\
\hline \multicolumn{5}{|l|}{ Composição química } \\
\hline Matéria seca & 69,9 & 68,6 & 71,4 & 70,2 \\
\hline Matéria orgânica & 95,6 & 95,2 & 95,3 & 95,0 \\
\hline Proteína bruta & 13,2 & 12,3 & 12,3 & 12,0 \\
\hline Extrato etéreo & 0,93 & 1,02 & 0,84 & 0,92 \\
\hline Fibra em detergente neutro & 37,7 & 41,6 & 44,0 & 45,4 \\
\hline Fibra em detergente ácido & 27,5 & 29,0 & 30,6 & 29,5 \\
\hline Lignina & 4,35 & 5,00 & 5,38 & 5,27 \\
\hline Nutrientes digestíveis totais & 63,2 & 63,2 & 62,7 & 62,2 \\
\hline Cálcio & 0,66 & 0,66 & 0,66 & 0,66 \\
\hline Fósforo & 0,29 & 0,29 & 0,29 & 0,29 \\
\hline
\end{tabular}

1 Tratamento $=\%$ de bagaço de cana-de-açúcar in natura adicionado ao bagaço de cana-de-açúcar tratado a pressão e vapor; ${ }^{2}$ Bagaço de cana-de-açúcar in natura - obtido pela moagem convencional; ${ }^{3}$ Bagaço de cana-de-açúcar in natura - obtido por difusão; ${ }^{4}$ Bagaço de cana-de-açúcar tratado sob pressão e vapor; ${ }^{5}$ Bagaço de cana-de-açúcar in natura.

ções, foram misturados manualmente e fornecidos como dieta total duas vezes ao dia (6 h e $18 \mathrm{~h})$.

O período experimental teve duração de 90 dias. Os primeiros 30 dias foram destinados à adaptação dos animais às instalações e às rações experimentais e o restante do período foi dividido em quatro subperíodos de 15 dias (11 primeiros para adaptação dos animais às rações e 4 para coleta de dados e amostras).

Os dados de consumo de matéria seca (MS) por animal por dia foram obtidos pela diferença entre a quantidade de alimento fornecida e a recusada. Foram obtidas amostras da ração oferecida e das sobras nos quatro dias de coleta. Diariamente, as fezes foram totalmente pesadas e amostras de $5 \%$ do total foram congeladas a $-10^{\circ} \mathrm{C}$. Ao final do experimento, as amostras foram descongeladas, compostas por animal e subperíodo e posteriormente foram secas em estufa de ventilação forçada a $55^{\circ} \mathrm{C}$ por 72 horas. Em seguida, foram trituradas em moinhos tipo Wiley, primeiramente em peneira com crivos de $2 \mathrm{~mm}$ e depois em peneiras de $1 \mathrm{~mm}$, para determinação dos teores de: MS, conforme descrito por Silva (1990); matéria mineral (MM), extrato etéreo (EE) e proteína bruta (PB), de acordo com AOAC (1990); fibra em detergente ácido (FDA), de acordo com Van Soest et al. (1991); e lignina, de acordo com Goering \& Van Soest (1970). Os teores de fibra em detergente neutro (FDN) foram determinados segundo metodologia descrita por Mertens (1997), pela técnica fiber bags (Ankom), utilizando-se amilase e sulfito de sódio. O extrato etéreo (EE) nas fezes foi determinado com éter de petróleo adicionado de $10 \%$ de ácido acético para liberação dos ácidos graxos (Mattos \& Palmquist, 1974).

As amostras de conteúdo ruminal foram coletadas no $13^{\circ}$ e $14^{\circ}$ dias de cada subperíodo a intervalos de 2 horas. Os horários de coleta foram determinados obedecendo aos horários de fornecimento da ração pela manhã, antes do fornecimento (0 hora) e 2, 4, 6, 8, e 10 horas após o fornecimento da ração.

As amostras foram obtidas em quatro pontos distintos do rúmen e filtradas em quatro camadas de tecido de algodão. Aproximadamente $200 \mathrm{~mL}$ de fluido ruminal filtrado foram utilizados para determinação imediata do $\mathrm{pH}$ de cada amostra, por meio de potenciômetro digital. Sequiencialmente, duas alíquotas de $25 \mathrm{~mL}$ do fluido ruminal foram retiradas, acrescentadas de $1,25 \mathrm{~mL}$ de solução $6 \mathrm{~N}$ de ácido clorídrico e congeladas a $-10^{\circ} \mathrm{C}$ para posterior determinação do nitrogênio amoniacal $\left(\mathrm{N}-\mathrm{NH}_{3}\right)$ e dos ácidos graxos voláteis ( $\mathrm{AGV}$ ).

As amostras foram descongeladas e centrifugadas a $11.000 \mathrm{~g}$ a $4^{\circ} \mathrm{C}$ durante 20 minutos. Uma fração do sobrenadante foi utilizada para determinação de $\mathrm{N}-\mathrm{NH}_{3}$, de acordo com o método colorimétrico descrito por Chaney \& Marbach (1962) e adaptado para utilização em placas de microtítulo com leitura em aparelho do tipo Elisa Reader com absorbância de 550 nanômetros. O restante do sobrenadante foi utilizado para determinação dos $\mathrm{AGV}$, de acordo com Palmquist \& Conrad (1971), utilizando-se cromatógrafo 
líquido gasoso. O ácido 2-etilbutírico foi utilizado como padrão interno e o nitrogênio como gás de arraste.

A análise estatística dos dados referentes ao ensaio de digestibilidade dos nutrientes foi realizada pelo procedimento GLM do programa estatístico SAS (1991). As variáveis $\mathrm{pH}, \mathrm{AGV}$ e $\mathrm{N}-\mathrm{NH}_{3}$ foram analisadas como parcelas subdivididas no tempo e analisadas pelo Proc Mixed, que define as variáveis fixas e aleatórias para análise.

Os efeitos de tratamento, animal e período foram testados em relação às parcelas. A interação horário de coleta $x$ tratamento foi testada em comparação às subparcelas. As médias das variáveis que apresentaram respostas significativas foram comparadas pelo teste Tukey a $5 \%$ de probabilidade utilizando-se o comando LSMEANS/PDIFF.

\section{Resultados e Discussão}

Os consumos de MS, MO, FDN e PB observados com a utilização de BIN obtido por difusão foram menores $(\mathrm{P}<0,05)$ que os consumos determinados com utilização de BIN obtido pelo método convencional de moagem (Tabela 2). Esses dados estão de acordo com os descritos por Torres et al. (2003), que avaliaram rações contendo $5,15,25$ e $35 \%$ de bagaço de cana-de-açúcar na alimentação de bezerros em crescimento e observaram efeito quadrático dos níveis de bagaço sobre o consumo de MS, que aumentou até o teor de $25 \%$ de bagaço. Esses autores concluíram que esse aumento esteve relacionado ao conteúdo de fibra da ração, que teve efeito direto sobre o consumo voluntário, por alterar os padrões de fermentação e a taxa de passagem da dieta. Adicionalmente, Ezequiel \& Andrade (1988) afirmaram que a utilização do bagaço de cana-de-açúcar afeta negativamente a utilização de fibra bruta e MS das dietas.

A utilização do BIN obtido pelo método de difusão não teve efeito significativo $(\mathrm{P}>0,05)$ sobre a digestibilidade aparente de MS, MO, PB, FDN, FDA e EE no trato digestório total em comparação ao fornecimento de BIN obtido pelo método convencional de moagem (Tabela 2). Hausknecht (1996) forneceu dietas com e sem fonte de fibra íntegra ( $8 \%$ de BIN ou cana-de-açúcar) em dietas com $50 \%$ de concentrado e BTPV como principal volumoso para bovinos em confinamento e não encontrou diferença significativa ( $\mathrm{P}>0,05)$ na digestibilidade da MS, MO, FDN, FDA e EE. A digestibilidade da MS neste trabalho foi superior à observada por esse autor quando forneceu as dietas com $8 \%$ de BIN como fonte de fibra íntegra. As digestibilidades de FDN e FDA foram semelhantes e não diferiram $(\mathrm{P}>0,05)$ entre os tipos de bagaço utilizados. Hausknecht (1996) encontrou valores em torno de 44 e $45 \%$ de digestibilidade de FDN e a FDA, respectivamente, para as dietas com $8 \%$ de BIN como fonte de fibra íntegra. Segundo esse autor, esse fato pode estar relacionado à baixa qualidade e baixa taxa de degradação do tipo da fibra da dieta (BIN ou canade-açúcar).

Geralmente, os volumosos apresentam diferenças na digestibilidade da FDN e da FDA, pois o bagaço in natura apresenta porção mais digerível da parede celular. No caso de dietas com BTPV, esta afirmação não é verdadeira, pois a fração hemicelulose do bagaço de cana-de-açúcar é quase totalmente transformada em açúcares durante o tratamento sob pressão e vapor, portanto, tanto a FDN quanto a FDA são encontradas em teores semelhantes.

$\mathrm{O}$ consumo de $\mathrm{PB}$ diferiu $(\mathrm{P}<0,05)$ entre os tratamentos (Tabela 2), provavelmente em virtude do baixo consumo de MS e da concentração de PB na dieta com maior porcentagem de bagaço in natura obtido por difusão. A digestibilidade aparente da $P B$ variou de 66,9 a 71,1\% e não diferiu $(P>0,05)$ entre rações experimentais, resultados similares aos encontrados por Hausknecht (1996), de 66,1\%. De acordo com Lanna \& Boin (1990), a ocorrência de compostos fenólicos no BTPV tem sido descrita como uma das causas da baixa digestibilidade da PB. Adicionalmente, Bulle et al. (2002b) afirmaram que a exigência de proteína metabolizável em rações com BTPV pode ser alterada pelos compostos fenólicos produzidos durante a hidrólise, uma vez que esses compostos inibem a digestão e absorção da proteína no intestino.

Os resultados de digestibilidade da MS e dos nutrientes no trato digestório total ratificam os de desempenho, que não diferiram $(\mathrm{P}>0,05)$ entre as rações experimentais. Dessa forma, a utilização de bagaço in natura obtido por difusão não prejudicou o desempenho e a digestibilidade da MS e dos nutrientes no trato digestório total em comparação à utilização do bagaço in natura obtido por moagem.

Não houve diferença $(\mathrm{P}>0,05)$ nos valores médios diários de $\mathrm{pH}$ ruminal e da concentração de nitrogênio amoniacal $\left(\mathrm{N}-\mathrm{NH}_{3}\right)$ entre as dietas (parcelas) e interação tratamento $\times$ tempo (Tabela 3 ). No entanto, o pH ruminal e a concentração de $\mathrm{N}-\mathrm{NH}_{3}$ apresentaram variações $(\mathrm{P}<0,05)$ no decorrer do dia (subparcelas), caracterizando a curvapadrão de fermentação ruminal.

Os dados de $\mathrm{pH}$ sugerem que as rações experimentais apresentaram padrão de fermentação ruminal adequado à ação de bactérias celulolíticas, mesmo com a utilização de $50 \%$ de concentrado e BTPV como principal volumoso, sem a adição de tamponantes e ionóforos. Os valores encontrados neste trabalho encontram-se na faixa considerada adequada para dietas com maior porcentagem de volumoso. 
Tabela 2 - Consumo e coeficientes de digestibilidade aparente dos nutrientes das rações experimentais no trato digestório total

\begin{tabular}{|c|c|c|c|c|c|c|}
\hline \multirow[t]{2}{*}{ Item } & \multicolumn{4}{|c|}{ Tratamento $^{1}$} & \multirow[t]{2}{*}{ Erro-padrão ${ }^{4}$} & \multirow[t]{2}{*}{$\mathrm{P}^{5}$} \\
\hline & $\begin{array}{c}5 \% \mathrm{BINmoa}^{2}+ \\
45 \% \text { BTPV }\end{array}$ & $\begin{array}{c}5 \% \text { BINdif }^{3}+ \\
45 \% \text { BTPV }\end{array}$ & $\begin{array}{c}10 \% \text { BINdif }+ \\
45 \% \text { BTPV }\end{array}$ & $\begin{array}{l}15 \% \text { BINdif }+ \\
45 \% \text { BTPV }\end{array}$ & & \\
\hline \multicolumn{7}{|c|}{ Matéria seca } \\
\hline Consumo, kg/dia & $9,8 \mathrm{a}$ & $8,6 \mathrm{~b}$ & $8,9 b$ & $7,4 \mathrm{c}$ & 0,2375 & 0,0023 \\
\hline Digestibilidade, \% & 68,4 & 66,8 & 66,9 & 66,6 & 1,0723 & 0,6465 \\
\hline \multicolumn{7}{|c|}{ Matéria orgânica } \\
\hline Consumo, kg/dia & $9,3 \mathrm{a}$ & $8,2 \mathrm{~b}$ & $8,4 \mathrm{~b}$ & $7,0 \mathrm{c}$ & 0,2188 & 0,0017 \\
\hline Digestibilidade, $\%$ & 69,8 & 68,8 & 69,0 & 69,2 & 1,0517 & 0,9213 \\
\hline \multicolumn{7}{|c|}{ Fibra em detergente neutro } \\
\hline Consumo, kg/dia & $3,7 \mathrm{a}$ & $3,6 \mathrm{a}$ & $3,8 \mathrm{a}$ & $3,1 b$ & 0,126 & 0,0388 \\
\hline Digestibilidade, $\%$ & 53,6 & 55,1 & 54,9 & 54,2 & 2,157 & 0,9256 \\
\hline \multicolumn{7}{|c|}{ Fibra em detergente ácido } \\
\hline Consumo, kg/dia & 2,7 & 2,5 & 3,0 & 2,0 & 0,221 & 0,0804 \\
\hline Digestibilidade, \% & 51,3 & 49,2 & 54,8 & 45,1 & 3,468 & 0,3378 \\
\hline \multicolumn{7}{|c|}{ Proteína bruta } \\
\hline Consumo, kg/dia & $1,3 \mathrm{a}$ & $1,0 \mathrm{bc}$ & $1,1 \mathrm{ab}$ & $0,90 \mathrm{c}$ & 0,061 & 0,0286 \\
\hline Digestibilidade, $\%$ & 70,2 & 66,9 & 69,0 & 71,1 & 2,252 & 0,6175 \\
\hline \multicolumn{7}{|c|}{ Extrato etéreo } \\
\hline Consumo, kg/dia & 0,09 & 0,09 & 0,07 & 0,07 & 0,008 & 0,1792 \\
\hline Digestibilidade, \% & 63,3 & 64,9 & 56,2 & 69,1 & 6,277 & 0,5680 \\
\hline
\end{tabular}

1 Tratamento $=\%$ de bagaço de cana-de-açúcar in natura adicionado ao bagaço de cana-de-açúcar tratado à pressão e vapor; ${ }^{2}$ Bagaço de cana-de-açúcar in natura - obtido por moagem convencional; ${ }^{3}$ Bagaço de cana-de-açúcar in natura - obtido por difusão; ${ }^{4}$ Erro-padrão da média; ${ }^{5}$ Probabilidade de efeito significativo $(P<0,05)$ entre os bagaços; a,b,c Médias seguidas de letras distintas, na mesma linha, diferem $(P<0,05)$ pelo teste Tukey.

De acordo com Valadares Filho \& Pina (2006), o pH ruminal pode variar de 5,5 a 7,2, com valores baixos de $\mathrm{pH}$ detectados em intervalos de tempo curtos, após a alimentação dos animais com dietas ricas em concentrado, enquanto, para rações com maior participação de volumosos, os valores oscilam entre 6,2 e 7,0 (Owens \& Goetsch, 1988).

Os valores observados para concentração de $\mathrm{N}-\mathrm{NH}_{3}$ no rúmen foram superiores a $10 \mathrm{mg} / \mathrm{dL}$ de fluido ruminal, valor mínimo recomendado para a máxima degradação do BTPV. Tendência semelhante foi observada por Hausknecht (1996) em pesquisa com rações contendo principalmente BTPV com ou sem fonte de fibra íntegra. Esse autor não observou diferença entre as rações, mas verificou aumento na concentração de amônia, que atingiu valores máximos 2 horas após o fornecimento dos alimentos.

A concentração molar dos ácidos acético, propiônico e butírico (Tabela 4) não diferiu ( $\mathrm{P}>0,05)$ entre os tratamentos (parcelas) nem quando considerada a interação tratamento $\times$ tempo, no entanto, apresentou variações $(\mathrm{P}<0,05)$ no tempo (subparcelas).

A manutenção dos valores de $\mathrm{pH}$ acima de 6,0 com a inclusão de BIN pode ter contribuído para manter estável a ação das bactérias celulolíticas. Assim, os valores de ácido acético mantiveram-se estáveis e em concentrações mais elevadas durante a maior parte do dia, indicando bom aproveitamento da porção fibrosa das rações.

Castro \& Machado (1989) verificaram maior produção dos ácidos propiônico e butírico em animais alimentados com ração contendo BTPV como volumoso exclusivo. Segundo esse autor, este resultado indica que a hemicelulose transformada em carboidratos solúveis foi degradada no rúmen produzindo principalmente ácido propiônico, o que não foi observado neste trabalho, uma vez que a inclusão de bagaço in natura e a redução da quantidade de BTPV nas rações experimentais não prejudicaram a produção de propionato e butirato no rúmen.

De acordo com Owens \& Goestsch (1988), a quantidade de ácidos graxos voláteis no fluido ruminal é reflexo da atividade microbiana e da taxa de absorção pela parede ruminal. Esta proporção varia com o tipo de substrato, a ingestão, a freqüência de alimentação, a taxa de diluição e a osmolaridade. Apesar da redução progressiva de BTPV nas rações com a inclusão do bagaço in natura, não houve alteração significativa na concentração total de ácidos graxos voláteis, portanto, o bagaço in natura proveniente de difusores como fonte de fibra íntegra pode 
Tabela 3 - pH do líquido ruminal e concentração de nitrogênio amoniacal $\left(\mathrm{N}^{-} \mathrm{NH}_{3}\right)$ nos animais alimentados com as rações experimentais

\begin{tabular}{|c|c|c|c|c|c|}
\hline \multirow[t]{2}{*}{ Tempo 4} & \multicolumn{4}{|c|}{ Tratamento ${ }^{1}$} & \multirow[t]{2}{*}{ Subparcela $^{5}$} \\
\hline & $\begin{array}{c}5 \% \mathrm{BINmoa}^{2}+ \\
45 \% \mathrm{BTPV}\end{array}$ & $\begin{array}{c}5 \% \text { BINdif }^{3}+ \\
45 \% \text { BTPV }\end{array}$ & $\begin{array}{l}10 \% \text { BINdif }+ \\
45 \% \text { BTPV }\end{array}$ & $\begin{array}{c}15 \% \text { BINdif + } \\
45 \% \text { BTPV }\end{array}$ & \\
\hline \multicolumn{6}{|c|}{$\mathrm{pH}$} \\
\hline 0 & 6,8 & 6,9 & 6,7 & 7,0 & $6,9 a$ \\
\hline 2 & 6,6 & 6,6 & 6,7 & 6,9 & $6,7 b$ \\
\hline 4 & 6,5 & 6,5 & 6,5 & 6,7 & $6,6 \mathrm{~cd}$ \\
\hline 6 & 6,4 & 6,4 & 6,4 & 6,6 & $6,5 \mathrm{e}$ \\
\hline 8 & 6,5 & 6,4 & 6,5 & 6,5 & $6,5 \mathrm{de}$ \\
\hline 10 & 6,5 & 6,6 & 6,6 & 6,7 & $6,6 b c$ \\
\hline Parcela $^{6}$ & 6,6 & 6,6 & 6,6 & 6,7 & \\
\hline \multicolumn{6}{|c|}{$\mathrm{N}-\mathrm{NH}_{3}$ ruminal $(\mathrm{mg} / \mathrm{dL})$} \\
\hline 0 & 12,4 & 11,9 & 13,2 & 11,9 & $12,4 \mathrm{~cd}$ \\
\hline 2 & 21,5 & 21,9 & 21,9 & 20,3 & $21,4 \mathrm{a}$ \\
\hline 4 & 17,2 & 17,7 & 20,0 & 22,3 & $19,3 b$ \\
\hline 6 & 14,6 & 13,7 & 12,6 & 16,5 & $14,4 \mathrm{c}$ \\
\hline 8 & 12,3 & 11,6 & 9,1 & 12,0 & $11,3 \mathrm{~d}$ \\
\hline 10 & 10,4 & 10,2 & 9,0 & 13,8 & $10,9 \mathrm{~d}$ \\
\hline Parcela 6 & 14,7 & 14,5 & 14,3 & 16,1 & \\
\hline
\end{tabular}

${ }^{1}$ Tratamento $=\%$ de bagaço de cana-de-açúcar in natura adicionado ao bagaço de cana-de-açúcar tratado a pressão e vapor; ${ }^{2}$ Bagaço de cana-deaçúcar in natura - obtido por moagem convencional; ${ }^{3}$ Bagaço de cana-de-açúcar in natura-obtido por difusão; ${ }^{4}$ Horas após o fornecimento da ração pela manhã; ${ }^{5}$ Média das subparcelas (tempo); ${ }^{6}$ Média das parcelas (tratamentos); a,b,c,d,e Médias seguidas de letras distintas na mesma linha diferem $(P<0,05)$ pelo teste Tukey.

Tabela 4 - Concentração molar (mM/L) dos ácidos acético, propiônico e butírico no fluido ruminal dos animais alimentados com as rações experimentais

\begin{tabular}{|c|c|c|c|c|c|}
\hline \multirow[t]{2}{*}{ Tempo 4} & \multicolumn{4}{|c|}{ Tratamento ${ }^{1}$} & \multirow[t]{2}{*}{ Subparcela } \\
\hline & $\begin{array}{c}5 \% \mathrm{BINmoa}^{2}+ \\
45 \% \mathrm{BTPV}\end{array}$ & $\begin{array}{c}5 \% \text { BINdif }^{3}+ \\
45 \% \text { BTPV }\end{array}$ & $\begin{array}{c}10 \% \text { BINdif }+ \\
45 \% \text { BTPV }\end{array}$ & $\begin{array}{l}15 \% \text { BINdif }+ \\
45 \% \text { BTPV }\end{array}$ & \\
\hline \multicolumn{6}{|c|}{ Ácido acético } \\
\hline 0 & 82,3 & 80,8 & 72,6 & 74,1 & $77,5 \mathrm{c}$ \\
\hline 2 & 100,9 & 91,7 & 89,7 & 91,7 & $93,6 a$ \\
\hline 4 & 95,7 & 92,0 & 88,6 & 88,2 & $91,2 \mathrm{a}$ \\
\hline 6 & 97,7 & 88,7 & 87,7 & 88,0 & $90,6 \mathrm{ab}$ \\
\hline 8 & 90,3 & 90,9 & 91,4 & 90,4 & $90,8 \mathrm{a}$ \\
\hline 10 & 86,4 & 85,4 & 82,8 & 87,8 & $85,7 \mathrm{~b}$ \\
\hline Parcela $^{6}$ & 92,2 & 88,3 & 85,5 & 86,7 & \\
\hline \multicolumn{6}{|c|}{ Ácido propiônico } \\
\hline 0 & 29,9 & 31,3 & 25,2 & 23,3 & $27,4 \mathrm{~b}$ \\
\hline 2 & 38,4 & 35,1 & 31,4 & 30,2 & $33,8 \mathrm{a}$ \\
\hline 4 & 33,9 & 34,1 & 30,9 & 29,9 & $32,3 \mathrm{a}$ \\
\hline 6 & 35,4 & 32,7 & 34,4 & 31,3 & $33,5 \mathrm{a}$ \\
\hline 8 & 32,8 & 34,8 & 35,3 & 32,2 & $33,8 \mathrm{a}$ \\
\hline 10 & 32,2 & 33,0 & 32,4 & 32,2 & $32,5 \mathrm{a}$ \\
\hline Parcela $^{6}$ & 33,8 & 33,5 & 31,6 & 29,9 & \\
\hline \multicolumn{6}{|c|}{ Ácido butírico } \\
\hline 0 & 16,2 & 15,1 & 11,9 & 12,4 & $13,9 \mathrm{~b}$ \\
\hline 2 & 19,5 & 17,3 & 16,0 & 14,8 & $16,9 \mathrm{a}$ \\
\hline 4 & 19,2 & 17,9 & 16,1 & 14,7 & $17,0 \mathrm{a}$ \\
\hline 6 & 20,3 & 16,3 & 17,3 & 15,7 & $17,4 \mathrm{a}$ \\
\hline 8 & 19,0 & 18,4 & 17,3 & 15,8 & $17,7 \mathrm{a}$ \\
\hline 10 & 18,2 & 17,4 & 15,9 & 15,6 & $16,8 \mathrm{a}$ \\
\hline Parcela 6 & 18,7 & 17,0 & 15,8 & 14,8 & \\
\hline
\end{tabular}

1 Tratamento $=\%$ de bagaço de cana-de-açúcar in natura adicionado ao bagaço de cana-de-açúcar tratado a pressão e vapor; ${ }^{2}$ Bagaço de cana-deaçúcar in natura - obtido por moagem convencional; ${ }^{3}$ Bagaço de cana-de-açúcar in natura - obtido por difusão; ${ }^{4}$ Horas após o fornecimento da ração pela manhã; ${ }^{5}$ Média das subparcelas (tempo); ${ }^{6}$ Média das parcelas (tratamentos); ${ }^{a, b}, \mathrm{c}$ Médias seguidas de letras distintas na mesma linha diferem $(P<0,05)$ pelo teste Tukey. 
Tabela 5 - Concentração total dos ácidos graxos voláteis (mM/L) e relação acetato/propionato no fluido ruminal dos animais alimentados com as rações experimentais

\begin{tabular}{ccccc}
\hline Tempo $^{4}$ & \multicolumn{4}{c}{ Tratamento $^{1}$} \\
\cline { 2 - 4 } & $5 \% \mathrm{BINmoa}^{2}+$ & $5 \% \mathrm{BINdif}^{3}+$ & $10 \% \mathrm{BINdif}+$ & $15 \%$ BINdif + \\
& $45 \% \mathrm{BTPV}$ & $45 \% \mathrm{BTPV}$ & $45 \% \mathrm{BTPV}$ & $45 \% \mathrm{BTPV}$ \\
\hline
\end{tabular}

$\begin{array}{lllll}0 & 133,2 & 131,6 & 108,8 & 116,2 \\ 2 & 161,6 & 148,1 & 141,4 & 122,5 \mathrm{c} \\ 4 & 152,9 & 147,7 & 139,3 & 148,0 \mathrm{a} \\ 6 & 157,5 & 141,0 & 143,3 & 14,1 \mathrm{ab} \\ 8 & 146,1 & 147,8 & 148,1 & 14,1 \mathrm{ab} \\ 10 & 141,1 & 139,6 & 135,3 & 146,1 \mathrm{ab} \\ \text { Parcelas }^{6} & 148,7 & 142,6 & 136,0 & 138,9 \mathrm{~b}\end{array}$

\begin{tabular}{|c|c|c|c|c|c|}
\hline \multirow[t]{2}{*}{ Parcelas 6} & 148,7 & 142,6 & 136,0 & 135, & \\
\hline & \multicolumn{5}{|c|}{ Acetato/propionato } \\
\hline 0 & 2,9 & 2,7 & 2,9 & 3,0 & $2,9 \mathrm{a}$ \\
\hline 2 & 2,8 & 2,6 & 3,0 & 3,1 & $2,9 \mathrm{a}$ \\
\hline 4 & 2,9 & 2,7 & 3,0 & 3,0 & $2,9 \mathrm{a}$ \\
\hline 6 & 2,8 & 2,7 & 2,7 & 2,8 & $2,8 \mathrm{~b}$ \\
\hline 8 & 2,8 & 2,7 & 2,8 & 2,8 & $2,8 \mathrm{~b}$ \\
\hline 10 & 2,8 & 2,6 & 2,6 & 2,7 & $2,7 b$ \\
\hline Parcelas 6 & 2,8 & 2,7 & 2,8 & 2,9 & \\
\hline
\end{tabular}

1 Tratamento $=\%$ de bagaço de cana-de-açúcar in natura adicionado ao bagaço de cana-de-açúcar tratado a pressão e vapor; ${ }^{2}$ Bagaço de cana-deaçúcar in natura - obtido por moagem convencional; ${ }^{3}$ Bagaço de cana-de-açúcar in natura - obtido por difusão; ${ }^{4}$ Horas após o fornecimento da ração pela manhã; ${ }^{5}$ Média das subparcelas (tempo); ${ }^{6}$ Média das parcelas (tratamentos); a,b,c Médias seguidas de letras distintas na mesma linha diferem $(P<0,05)$ pelo teste Tukey.

ser utilizado como substituto parcial do BTPV, pois não prejudica a concentração total de AGV.

O valor mais elevado da relação acetato/propionato ocorreu 4 horas após a alimentação (Tabela 5). O tratamento contendo $15 \%$ de BINDif diferiu $(\mathrm{P}<0,05)$ daquela com $5 \%$ de BINDif no tempo imediatamente anterior (0 hora) ao fornecimento das rações e 2 horas depois. Provavelmente a redução da quantidade de BTPV determinou aumento da relação acetato/propionato, em virtude do aumento nos teores de FDN e FDA das dietas experimentais.

\section{Conclusões}

A utilização de $15 \%$ de bagaço in natura obtido por difusão acrescido de $35 \%$ de bagaço tratado por pressão e vapor em rações com $50 \%$ de volumoso não prejudica a digestibilidade dos nutrientes e os parâmetros ruminais de bovinos de corte.

\section{Literatura Citada}

ASSOCIATION OF OFFICIAL ANALYTICAL CHEMISTS - AOAC. Official methods of analysis. 15.ed. Washington, D.C.: 1990. $1298 \mathrm{p}$.

BASTOS NETO, A.O. [2007]. Aspectos da extração de sacarose da cana-de-açúcar por difusão. Disponível em: http://unisystems.locaweb.com.br Acesso em: 2/10/2007.

BERNDT, A.; HENRIQUE, W.; LANNA, D.P.D. et al. Milho úmido, bagaço de cana e silagem de milho em dietas de alto teor de concentrado. 2. Composição corporal e taxas de deposição dos tecidos. Revista Brasileira de Zootecnia, v.31, n.5, p.2105-2112, 2002.

BORGES, I.; GONCALVES, L.C.; MORAIS, M.G. et al. Influência da dieta sobre o desaparecimento in situ da matéria seca, da matéria orgânica e da fibra em detergente neutro do bagaço de cana-deaçúcar auto-hidrolisado. Arquivo Brasileiro de Medicina Veterinária e Zootecnia, v.52, n.3, p.235-242, 2000.

BULLE, M.L.M.; RIBEIRO, F.G.; LEME, P.R. et al. Desempenho de tourinhos cruzados em dietas de alto teor de concentrado com bagaço de cana-de-açúcar como único volumoso. Revista Brasileira de Zootecnia, v.31, n.1, p.444-450, 2002 a.

BULLE, M.L.M.; RIBEIRO, F.G.; LEME, P.R. et al. Exigências líquidas de energia e proteína de tourinhos de dois grupos genéticos alimentados com dietas de alto teor de concentrado. Revista Brasileira de Zootecnia, v.31, n.1, p.436-443, 2002b.

CASTRO, F.B.; MACHADO, P.F. Avaliação do processo de digestão do bagaço de cana-de-açúcar tratado sob pressão e vapor. Boletim da Indústria Animal, v.46, p.213-217, 1989.

CHANEY, A.L.; MARBACH, E.P. Modified reagents for determination of urea and ammonia. Clinical Chemistry, v.8, p.130-132, 1962.

DELGADO, A.A. Tecnologia dos produtos agropecuários: Tecnologia do açúcar e das fermentações industriais. Piracicaba: Escola Superior de Agricultura Luiz de Queiroz, 1975. 209p.

EZEQUIEL, J.M.B.; ANDRADE, P. Avaliação de rações contendo bagaço de cana-de-açúcar e palha de arroz. Ingestão e digestibilidade. Revista da Sociedade Brasileira de Zootecnia, v. 17, n.5, p.446-455, 1988.

EZEQUIEL, J.M.B.; GALATI, R.L.; MENDES, A.R. et al. Desempenho e características de carcaça de bovinos Nelore em confinamento alimentados com bagaço de cana-de-açúcar e diferentes fontes energéticas. Revista Brasileira de Zootecnia, v.35, n.5, p.2050-2057, 2006.

GOERING, H.K.; Van SOEST, P.J. Forage fiber analysis (apparatus, reagents, procedures and some applications). Washington: USDA, 1970. 20p. (Agriculture Handbook, 379).

HAUSKNECHT, J.C. Efeito da fonte de fibra e do processamento físico do sorgo sobre o desempenho, digestibilidade e parâmetros ruminais de bovinos alimentados com rações 
à base de bagaço tratado sob pressão de vapor. Piracicaba: Escola Superior de Agricultura Luiz de Queiroz, 1996. 86p. Dissertação (Mestrado em Zootecnia) - Escola Superior de Agricultura Luiz de Queiroz, 1986.

HENRIQUE, W.; FILHO, J.A.B.; LEME, P.R. et al. Avaliação da silagem de grãos de milho úmido com diferentes volumosos para tourinhos em terminação: desempenho e características de carcaça. Revista Brasileira de Zootecnia, v.36, n.1, p.183-190, 2007.

LANNA, D.P.D.; BOIN, C. Efeito de bicarbonato de sódio, feno e bagaço "in natura" sobre a digestibilidade e o desempenho de zebuínos em crescimento alimentados com bagaço de cana auto-hidrolisado. Anais da Escola Superior de Agricultura “Luiz de Queiroz", v.47, p.417-434, 1990.

LANNA, D.P.D.; MORAIS, J.P.; BOIN, C. et al. Desempenho e composição corporal de novilhas alimentadas com dois níveis de concentrado e bagaço de cana submetidos a diferentes processos de hidrólise. Revista Brasileira de Zootecnia, v.28, n.2, p.412-420, 1999.

MAGALHÃES, L.R.G.; VASQUEZ, H.M.; SILVA, J.F.C. Bagaço hidrolisado e ponta de cana-de-açúcar (Sacharum officinarum), associados a duas fontes protéicas, na engorda de bovinos em confinamento. Revista Brasileira de Zootecnia, v.28, n.4, p.822-830, 1999

MATTOS, W.; PALMQUIST, D.L. Increased polyunsaturated fatty acid yields in milk of cows fed protected fat. Journal of Dairy Science, v.57, p.1050-1054, 1974.

MERTENS, D.R. Creating a system for meeting the fiber requirements of dairy cows. Journal of Dairy Science, v.80, p.1463-1481, 1997.
NATIONAL RESEARCH COUNCIL - NRC. Nutrient requirements of beef cattle. 7.ed. Washington, D.C.: National Academy Press, 1996. 234p.

NUSSIO, L.G.; BALSALOBRE, M.A. Utilização de resíduos fibrosos da industrialização da cana-de-açúcar na alimentação de bovinos. In: SIMPÓSIO SOBRE NUTRIÇÃO DE BOVINOS, 5., 1993, Piracicaba. Anais... Piracicaba: Fundação de Estudos Agrários Luiz de Queiroz, 1993. p.127-150.

OWENS, F.N.; GOETSCH, A.L. Ruminal fermentation. In: CHURCH, D.C. (Ed.). The ruminat animal digestive physiology and nutrition. Englewood Cliffs: Simon \& Schuster, 1988. p. $145-171$.

PALMQUIST, V.T.; CONRAD, H. Origin of plasma fatty acids in lactating cows fed high fat diets. Journal of Dairy Science, v.54, p.1025-1033, 1971.

STATISTICAL ANALYSIS SYSTEM - SAS. SAS/STAT: user's guide. Cary: 1991. 1028p.

TORRES, L.B.; FERREIRA, M.A.; VÉRAS, A.S.C. et al. Níveis de bagaço de cana e uréia como substituto ao farelo de soja em dietas para bovinos leiteiros em crescimento. Revista Brasileira de Zootecnia, v.32, n.3, p.760-767, 2003.

VALADARES FILHO, J.C.; PINA, D.S. Fermentação ruminal. In: BERCHIELLI, T.T.; PIRES, A.V.; OLIVEIRA, S.G. (Eds.). Nutrição de ruminantes. 1.ed. Jaboticabal: Funep, 2006. p.151-182.

Van SOEST, P.J.; ROBERTSON, J.B.; LEWIS, B.A. Methods for dietary fiber, neutral detergent fiber and nonstarch polysaccharides in ration to animal nutrition. Journal of Dairy Science, v.74, p.3583-3597, 1991 . 